\title{
A PREPARAÇÃO DE UMA EQUIPE DO PROJETO RONDON: NA PERSPECTIVA DOS ELEMENTOS POSITIVOS
}

\author{
Renan Valério Eduvirgem \\ Universidade Estadual de Maringá \\ georenanvalerio@gmail.com \\ Kimberli Pauline Berwig \\ Universidade Estadual de Maringá \\ kimberwig@hotmail.com
}

\author{
André Gustavo da Cunha Ramalho \\ Universidade Federal do Pampa \\ agcramalho@gmail.com \\ Fernando de Souza Silva \\ Universidade Estadual de Maringá \\ fernandofss95@gmail.com
}

\begin{abstract}
Resumo
Neste trabalho são apresentados quatro elementos considerados como positivos na preparação dos rondonistas de uma IES pública e que se espera que possam ser úteis para outras equipes. Em uma IES pública, a verba para tais finalidades é escassa e seu processo de obtenção é burocrático. Sendo assim, como primeiro elemento positivo, destaque-se o levantamento de $\mathrm{R} \$ 1.275,00$ líquidos com a venda de 150 pizzas. O segundo elemento, foi uma capacitação em liderança facilitadora, fruto de uma parceria com uma consultoria em desenvolvimento de pessoas. O terceiro elemento positivo foi o resultado da busca pela capacitação da equipe: a aproximação dos rondonistas com a comunidade do entorno da universidade. Como último ponto a destacar, ressalta-se o envolvimento de suplentes (professores e alunos) nas ações de capacitação. O objetivo era que, em caso de necessidade de assumir o posto de alguém, os suplentes já estivessem envolvidos com o projeto.

Palavras-chave: Projeto Rondon. Preparação. Desenvolvimento Social. Liderança Facilitadora.

\section{THE PREPARATION OF A PROJECT TEAM RONDON: IN VIEW OF THE POSITIVE ELEMENTS}

\begin{abstract}
This paper presents four elements considered as positive in the preparation of rondonistas of a public "IES" and it is expected that may be useful for other teams. In a public "IES", the budget for such purposes is scarce and its obtaining process is bureaucratic. Finally, we raised R \$1,275.00 net by selling 150 pizzas. The second element was a training in facilitative leadership, the result of a partnership with a consulting people development. The third positive development was a result of the search for staff training: the approach of rondonistas with the surrounding university community. The last, but not least point to highlight was the involvement of deputies (teacher and student) in training activities. The aim was that in case of need to take someone's post, they were already involved with the project.
\end{abstract}

Keywords: Projeto Rondon. Preparation. Social Development. Lead Facilitator.

\section{LA PREPARACIÓN DE UN EQUIPO DE PROYECTO RONDON: EN VISTA DE LOS ELEMENTOS POSITIVOS}

\section{Resumen}

Este artículo presenta cuatro elementos considerados como positivos la preparación de rondonistas un IES público y se espera que pueda ser útil para otros equipos. En una IES pública, el presupuesto para tales fines es escasa y su proceso de obtención es burocrático. Por último, hemos planteado R \$1.275.00 netos por la venta de 150 pizzas. El segundo elemento, que era un entrenamiento en liderazgo facilitador, el resultado de una sociedad con un desarrollo de las personas consultar. El tercer acontecimiento positivo fue el resultado de la búsqueda de la formación del personal: el enfoque de rondonistas con la comunidad universitaria de los alrededores. La última, pero no menos importante punto a destacar fue la participación de los diputados (profesor y alumno) en actividades de formación. El objetivo era que en caso de necesidad de tomar el post de alguien, que ya estaban involucrados con el proyecto.

Palavras clave: Projeto Rondon. Preparación. Desarrollo Social. Facilitador de Plomo. 


\section{INTRODUÇÃO}

O Projeto Rondon em seu início teve como propósito promover o desenvolvimento social através dos estudantes universitários, com objetivo de conduzir a juventude a participar do processo de integração nacional, baseado na filosofia humanística do Marechal Cândido Mariano da Silva Rondon.

Idealizado no período em que os militares governavam o país, iniciado por Costa e Silva (1967-1969) a João Batista Figueiredo (1979-1985), sendo que no Governo de Geisel (1974-1979) ocorreu a intenção do fortalecimento do projeto, propiciando mais recursos para intensificar a participação dos estudantes no que tange o processo de desenvolvimento social e econômico brasileiro.

O projeto decaiu com o governo de José Sarney (1985-1990), justificado pelo fim da posição militarista frente ao governo no Brasil (SANTOS e MENDES, 2005).

Em 2005 o Projeto Rondon retorna com pauta dos programas governamentais, sendo coordenado pelo Ministério da Defesa. Deste modo o Projeto Rondon é uma ação do governo federal, que busca soluções para o desenvolvimento e integração social e construção da cidadania de forma sustentável de comunidades carentes, melhorando a qualidade de vida das comunidades atingidas pela ação. Além disso, proporciona aos estudantes do ensino superior a experiência de aplicar os conteúdos estudados e desenvolvidos na instituição de ensino superior (IES), aproximando-os da realidade e da demanda que algumas localidades do Brasil apresentam sendo, portanto, uma experiência acadêmica e cívica.

Parte-se da pretensão de executar diversas atividades por meio da cooperação de uma equipe interdisciplinar e unificada sob o propósito de promover ações que visam à capacitação da comunidade para o desenvolvimento local sustentável e autogestão, em que cada atividade deverá ser tratada com interdisciplinaridade pelos membros da equipe, focada nas necessidades e potenciais da cidade.

Para tal, faz-se necessária uma aproximação da comunidade e dos conhecimentos locais que explicitam a vocação de desenvolvimento endógeno. Isso se dá em boa parte durante e após a viagem precursora, momento no qual se conhece de uma maneira mais aprofundada o município no qual se desenvolverá a operação.

Os objetivos do artigo estão em aspectos da preparação do grupo, formado por alunos da Universidade Estadual de Maringá, participantes da Operação Itacaiúnas, realizada em julho de 2015, na explanação dos levantamentos de recursos financeiros, envolvimento com a comunidade local de Maringá, preparação da suplência e de liderança facilitadora. 
A preparação de uma equipe do Projeto Rondon: na perspectiva dos elementos positivos

O tema está relacionado à preparação das atividades do projeto, assim como seu planejamento. Ambas foram de extrema importância, pois houve maior capacidade técnica, recursos financeiros, organização do cronograma e otimização de tempo nas atividades em Água Azul do Norte (Pará), município que recebeu as atuações das atividades.

\section{MATERIAIS E MÉTODOS}

\subsection{Levantamento de recursos financeiros}

De modo a prevenir possíveis falhas durante as oficinas na operação, a equipe decidiu criar alguns protótipos do que seria desenvolvido no munícipio, assim, as atividades realizadas na cidade de origem, foram: receita de pão francês e croissant, queijo tipo minas frescal, queijo tipo petit-suisse, doce de leite, sabão feito a partir de óleo de cozinha usado, cisterna, biodigestor, composteira, horta orgânica, papel reciclado e artesanato.

O desenvolvimento dos protótipos foi muito importante para avaliar se o que a equipe havia planejado de fato iria ser concretizado na prática de maneira efetiva. A importância dos protótipos foi tão grande que, dentre as atividades citadas anteriormente, percebeu-se que não era viável apresentar em uma das oficinas o desenvolvimento de um biodigestor, devido ao baixo resultado que o protótipo apresentou e pelo tempo a ser destinado para a produção do gás. Mediante a estes fatores, decidiu-se cancelar essa oficina.

Além dos protótipos, foram confeccionados adesivos para a divulgação do projeto na cidade de destino e também se gastou com materiais para levar até o munícipio para a realização das oficinas.

Para levantar fundos de modo a custear esses gastos, a equipe decidiu vender pizzas. Foram compradas 150 pizzas a um preço de $\mathrm{R} \$$ 6,50 cada uma, as quais foram vendidas a $\mathrm{R} \$$ 15,00 cada uma. Dessa maneira, obteve-se um lucro total de $\mathrm{R} \$ 1.275,00$, quantia suficiente para arcar com todos os gastos previstos.

\subsection{Envolvimento com a comunidade local de Maringá}

Nas reuniões, ocorridas na Universidade Estadual de Maringá, desde abril de 2015, fez-se necessária a articulação com a comunidade civil e jurídica de Maringá. O objetivo foi de aprofundamento no conhecimento das atividades que posteriormente seriam realizadas. 
Todas as atividades tiveram estudos prévios através da internet, livros e experiências de profissionais na área. Mas as maiores parcerias, no município, sem hierarquia de importância e/ou cronológica, ficaram em torno da (o):

- Associação dos Aposentados da Vila Esperança;

- Prefeitura Municipal de Maringá com a Secretaria da Mulher, Secretaria Municipal de Serviços Públicos;

- EMATER - Empresa de Assistência Técnica e Extensão Rural;

- SENAR - Serviço Nacional de Aprendizagem Rural;

- ACIM - Associação Comercial e Empresarial de Maringá.

A Associação dos Aposentados da Vila Esperança esteve de portas abertas para parceria entre o grupo do Projeto Rondon e os moradores do bairro. Foi realizada uma reunião entre os membros do projeto e os lideres da associação e de outras entidades do bairro com a finalidade de firmar uma parceria para aplicação de atividades relacionadas principalmente com o meio ambiente.

A Secretaria Municipal da Mulher forneceu um curso gratuito de artesanato com duração de 8 horas, nos dia 27 de maio e 03 de junho, no período da manhã. O curso teve como enfoque a feitura manual de tulipas e vários tipos de flores em tecidos, assim como fuxicos.

Maringá é referência nacional das Hortas Comunitárias Orgânicas no Brasil, com 27 hortas já instaladas que atende indiretamente mais de 2.800 pessoas e mais de 700 famílias (ALBUQUERQUE, 2012). Através da SEMUSP (Secretaria Municipal dos Serviços Públicos) foi possível realizar visita à duas dessas hortas comunitárias, do bairro Ebenezer e da Vila Esperança.

Em uma das visitas ao engenheiro agrônomo responsável pelas hortas pode-se compreender que trata-se de um programa do MDS (Ministério de Desenvolvimento Social e Combate a Fome) e PNAN (Política Nacional de Alimentação e Nutrição). Foi possível perceber a importância deste profissional diante a qualidade e elevada produção das hortas. A assistência técnica prestada pelo engenheiro resulta em alimentos saudáveis para a população local, sendo possível graças ao fomento dos programas do MDS e PNAN.

A EMATER (Empresa de Assistência Técnica e Extensão Rural) facilitou com dezenas de cartilhas sobre o CAR (Cadastro Ambiental Rural).

O SENAR ofereceu alguns cursos gratuitos, como: "Fabricação de produtos derivados de leite", "Agricultura Orgânica" e "Visita de técnicas e boas práticas de ordenha". 
O curso de derivados de leite, de 16 horas (13 a 14 de maio de 2015), ocorreu na Expoingá (Parque Internacional de Exposições Francisco Feio Ribeiro). O curso teve como objetivo desenvolver produtos como queijo minas frescal, coalho, mussarela, petit-suisse, doce de leite pastoso e em pedaços, bebida láctea fermentada, iogurte natural e outros.

Assim como o curso de "Agricultura Orgânica" com duração de 24 horas nos dias 18, 19 e 20 de junho, período integral, sendo a parte teórica realizada no auditório do Sindicato Rural de Maringá e a prática na Horta Comunitária da Vila Esperança.

Além das atividades supracitadas, foi realizada ainda, em parceria com o SENAR, uma visita de "Técnicas e boas práticas de Ordenha" na EXPOINGÁ.

Nos dias 05 e 06 de julho, a ACIM realizou uma capacitação exclusiva de 16 horas (período integral) para os rondonistas sobre captação de recursos federais, através do SICONV Sistema de Convênios.

A oficina em questão teve como objetivo principal a capacitação dos rondonistas, e também dos agentes públicos do poder executivo municipal, sobre as possibilidades de captação de recursos da esfera federal. A capacitação, em seu planejamento, teve como princípios explanar as transferências obrigatórias e voluntárias da união e os meios de inscrição de projetos para obtenção das mesmas.

\subsection{Preparação da suplência}

A amizade entre os rondonistas é fundamental para que haja interação entre todos, inclusive do suplente, tendo em vista que os planos almejados pelo grupo sejam alcançados.

Deste modo o suplente foi fundamental na equipe de rondonistas, pois este demonstrou determinação junto ao grupo, intensificando o empenho na produção das atividades, planejamento e execução de testes das mesmas para assim, identificar os supostos imprevistos que poderiam ocorrer no momento da aplicação das atividades na operação Itacaiúnas, no município de Água Azul do Norte, Pará.

O suplente da operação Itacaiúnas da Universidade Estadual de Maringá, foi excepcional durante o desenvolvimento das atividades, no planejamento das mesmas, no auxilio da organização do grupo, bem como nas capacitações. 
A preparação de uma equipe do Projeto Rondon: na perspectiva dos elementos positivos

\subsection{Liderança facilitadora}

Uma das etapas de preparação dos rondonistas foi um treinamento sobre "Liderança Facilitadora" com a consultora de desenvolvimento pessoal Luiza Carvalho Paterno Gadelha. Foi uma manhã de intenso treinamento onde participaram os rondonistas do grupo, além de outros interessados. Resgatou-se inicialmente o histórico de líderes ao longo dos anos, bem como suas características, até chegar ao estereótipo do líder atual e das qualidades esperadas desse.

Como diz a Endeavor Brasil, organização de apoio a empreendedorismo e empreendedores: "liderar nos dias de hoje não é apenas estar à frente de uma equipe, mas ser seguido por ela, nutrindo um sentimento de igualdade pela equipe, centrando em objetivos comuns, procurando causas e oportunidades de aprendizagem em situações de conflitos e tendo personalidade harmoniosa”. Assim, entra a liderança facilitadora, que de acordo com o Portal Educação (2015) "é considerada a capacidade do líder de inspirar, guiar e estimular os grupos por intermédio das características que deve desenvolver em si e também nos seus parceiros profissionais".

\section{RESULTADOS E ANÁLISES}

\subsection{Levantamento de recursos financeiros}

Para custear os gastos a equipe decidiu vender pizzas. Foram compradas 150 pizzas com valor de $\mathrm{R} \$$ 6,50 cada, as quais foram vendidas a $\mathrm{R} \$ 15,00$ cada. Assim, obtivemos lucro de $\mathrm{R} \$$ $1.275,00$, quantia que foi utilizada em todos os gastos previstos.

A etapa de levantamento de recursos foi de grande importância para o sucesso da operação. Esta etapa viabilizou a realização dos protótipos, que por sua vez, permitiu à equipe avaliar todas as possíveis falhas que poderiam ocorrer ao executar as oficinas no munícipio de destino. O resultado foi realmente plausível, pois não ocorreram falhas nas oficinas em que foram realizados os protótipos.

Além disso, o levantamento de recursos financeiros foi responsável por viabilizar a compra dos materiais para a realização da parte prática nas oficinas. Em outras palavras, o dinheiro arrecadado foi importante tanto na fase de preparação para a viagem quanto durante a operação.

\subsection{Envolvimento com a comunidade local de Maringá}


O envolvimento da equipe com a comunidade da cidade de origem foi muito importante pelo fato de possibilitar a relação com a população, órgãos públicos e instituições antes da viagem. Dessa forma, durante a operação, pode-se dizer que a equipe já estava muito mais preparada quando encontrou situações semelhantes em relação a este aspecto.

Além disso, o envolvimento com a comunidade trouxe, dentre outros benefícios, capacitações que foram essenciais para o desenvolvimento das atividades no munícipio de destino durante a operação. Dessa forma, estes contatos contribuíram muito para o sucesso da equipe durante as aplicações das atividades.

\subsection{Preparação da suplência}

Ter um suplente na equipe foi essencial, pois a cada semana que se passava o suplente demonstrava seu empenho com os amigos para que tudo desse certo. Os demais integrantes da equipe sentiam-se cada vez mais motivados, visto que o suplente esteve sempre presente nas reuniões, nas quais sua determinação potencializava em todo grupo a responsabilidade de não faltar e empenhar-se sempre mais.

Ante o exposto, é fundamental a presença e preparação do suplente junto à equipe, pois caso ocorra algum imprevisto com um dos integrantes, o suplente estará preparado para assumir e executar as atividades programadas.

\subsection{Liderança facilitadora}

A importância do treinamento de liderança facilitadora para os rondonistas foi muito grande, pois os mesmos formaram uma equipe, na qual faz-se necessário um trabalho de desenvolvimento interpessoal, reforçando o processo de confiança e comunicação entre todos. Uma equipe unida, com objetivos comuns, com uma boa comunicação e orientação, foi a chave para que o trabalho do grupo pudesse ser otimizado, respeitando as qualidades e defeitos de cada membro do time e usando-as a seu favor para construir um ambiente apropriado à criação das atividades e oficinas e à execução das mesmas.

De acordo com os estudos de Vendramini (2000), a liderança facilitadora é considerada a capacidade do líder de inspirar, guiar, estimular os grupos, por intermédio das características que deve desenvolver em si e também nos seus parceiros profissionais. 
A preparação de uma equipe do Projeto Rondon: na perspectiva dos elementos positivos

Como os rondonistas atuaram em uma cultura diferente, compartilhando conhecimentos e opiniões com pessoas desconhecidas, foi de fundamental valia este período preparatório. Um líder facilitador deve saber como aceitar diferentes ideias, sem deixar sua opinião prevalecer e sim, aspectos que se tornem positivos para todo o grupo.

\section{CONSIDERAÇÕES FINAIS}

O Projeto Rondon tem como objetivo desenvolvimento social e da cidadania de maneira sustentável.

A preparação das atividades foi realizada em grupo, planejando os custos e vendendo pizzas para se obter recursos necessários para desenvolvimento das atividades em Maringá (protótipos) e em Água Azul do Norte (materiais para as atividades).

O contato com a comunidade em Maringá foi importante para que ao chegar em Água Azul do Norte já existir uma experiência com os públicos alvos das atividades.

A participação da suplência no grupo do Rondon foi importante para que houvesse maior desempenho nas atividades, assim como a colaboração nas atividades.

As atividades desenvolvidas no Pará ocorreram dentro do previsto e com muito profissionalismo, pois houve grande planejamento e preparação dos rondonistas.

As atividades realizadas no município de Água Azul do Norte estavam pautadas nesse objetivo.

\section{REFERÊNCIAS}

ALBUQUERQUE, José Oliveira de. Horta Comunitária de Maringá: Inclusão Social e Produtiva. Federação Indústrias Estado do Paraná. 2012. Disponível em: < http://www.fiepr.org.br/nospodemosparana/>. Acesso em: 15 ago. 2015.

PORTAL EDUCAÇÃO. O líder age como um facilitador. Disponível em: <www.portaleducacao.com.br/administracao/artigos/17575/o-lider-age-como-um-facilitador>. Acesso em 15 nov 2016.

SANTOS, Maria da Soledade Simeão dos; MENDES, Isabel Amélia Costa. Projeto Rondon: a metodologia educativo assistencial de trabalho dos estagiários universitários. Esc. Anna Nery R. Enf, v.9, n.1, p.124-137, 2005.

VENDRAMINI, P. Liderança e mudança organizacional: as categorias essenciais do líder facilitador. 2000. 225 f. Dissertação (Mestrado em Engenharia de Produção) - Programa de PósGraduação da Engenharia de Produção e Sistemas. Universidade Federal de Santa Catarina, Florianópolis. 2000. 